\title{
Ameliorative effect of Alpha-tocopherol on E-cigarette liquid induced histomorphological changes in adrenal cortex of male Albino rats.
}

1. MBBS, M.Phil

Senior Lecturer Anatomy Jahalwan Medical College

2. MBBS, M.Phil

Demonstrator Biochemistry Bolan University of Medical and Health Sciences, Quetta

3. MBBS, M.Phil

Assistant Professor Biochemistry Margala Dental College

4. MBBS, M.Phil

Associate Professor Physiology Jahalwan Medical College

5. MBBS, M.Phil

Senior Lecturer Anatomy

Shifa International Medical College

6. BDS, M.Phil

Senior Lecture Oral Biology

Bolan University of Medical and

Health Sciences, Quetta

Correspondence Address:

Dr. Muhammad Imran Bajwa

Islamic International Medical College.

m_imranbajwa@yahoo.com

Article received on:

07/05/2020

Accepted for publication:

$24 / 09 / 2020$
Ali Ahmed ${ }^{1}$, Mehreen Lashari ${ }^{2}$, Muhammad Imran Bajwa ${ }^{3}$, Jahanzaib Lashari ${ }^{4}$, Syeda Sara Bano ${ }^{5}$, Dur Muhammad ${ }^{6}$

ABSTRACT... Objective: To study the ameliorative effect of Alpha-Tocopherol (Vitamin E) against E-cigarette induced histomorphalogical changes in adrenal cortex of male Albino rats. Study Design: Randomized Animal Control Trial. Setting: Department of Anatomy, Islamic International Medical College Rawalpindi in collaboration with National Institute of Health (NIH), Islamabad. Period: September 2018 to September 2019. Material \& Methods: 30 adult male albino rats were divided in three groups having 10 rats each. Normal diet and distilled water was given to control group (Group I) including 10 rats, for 4 weeks. The Rats of Group II were injected E-cigarette liquid $0.5 \mathrm{mg}$ per $\mathrm{kg}$ body weight per day diluted in 500ul normal saline intraperitoneally for 4 weeks. The experimental rats in Group III, in addition to E-cigarette liquid also received Vitamin E, 100mg per kg body weight per day mixed in daily diet. Dissection of the animals was done after completion of 4 weeks and adrenal gland was removed for histological analysis. Data was recorded and analyzed in SPSS ${ }^{\mathrm{TM}}$ version 21. Results: Alpha-Tocopherol restored the quantitative changes induced by E-Cigarette liquid in adrenal cortex in Group III, which was increased in the rats of Group II who were injected E-Cigarette liquid. Among microscopic parameters Orientation of cells, sinusoidal dilatation was significantly reduced in all adrenal cortex zones by Alpha-Tocopherol in Group III animals. Conclusion: The current study demonstrated that Alpha-Tocopherol had an ameliorative effect on histological changes caused by E-cigarette liquid on adrenal cortex.

Key words: $\quad$ Alpha-Tocopherol, Adrenal Cortex, E-cigarette Liquid.

Article Citation: Ahmed A, Lashari M, Bajwa MI, Lashari J, Bano SS, Muhammad D. Ameliorative effect of Alpha-tocopherol on E-cigarette liquid induced histomorphological changes in adrenal cortex of male Albino rats. Professional Med J 2021; 28(4):520-526. https://doi.org/10.29309/TPMJ/2021.28.04.4768

\section{INTRODUCTION}

The adrenal glands are paired glands located on the upper pole of the kidneys, surrounded by the perinephric fat. The adrenal gland consists of two parts adrenal cortex and adrenal medulla. ${ }^{1}$ The cortex part of the adrenal gland develops from intermediate mesoderm. ${ }^{2}$ Adrenal cortex is further divided into three concentric zones in which the cords of epsithelial cells have different orientation and they produce different types of steroid hormones. ${ }^{3}$ The Zona glomerulosa, which is the outer zone, secretes mineralocorticoids and aldosterone. Zona fasciculata, the thick middle zone and secretes glucocorticoids mainly cortisol. Zona reticularis, the inner zone consists of cells that secrets glucocorticoids and androgens. ${ }^{4,5}$ The adrenal glands regulate our body response to stress for example, the defensive action of anti-inflammatory adrenal hormones like cortisol helps to reduce negative and allergic reactions, such as swelling and inflammation which are due to alcohol, smoking cigarettes, drugs, environmental toxins, cancer, infection, and autoimmune disorders. ${ }^{6}$

An Electronic cigarette or E-cigarette is a handheld electronic device that mimics the effect of smoking a cigarette. It works by heating a liquid to create an aerosol, commonly called a "vapor" which is inhaled by the user. ${ }^{7}$ Use of e-cigarettes is generally mentioned as vaping. The fluid in the Electronic cigarette is called E-liquid which comprises of propylene glycol, vegetable glycerin, distal water, flavor agent and nicotine with 
optionally available doses of nicotine ranging from $0-24 \mathrm{mg} / \mathrm{ml} .{ }^{8}$ The main components of E-cigarette are lithium battery and a part called Atomizer, which contains the e-liquid and is vaporized by applying electrical current. ${ }^{9} \mathrm{E}$-cigarettes have not shown any benefit over conventional cigarette smoking cessation and not approved as an aid to smoking cessation by any international body such as Food and Drug Administration (FDA), USA or World Health Organization (WHO). ${ }^{10}$ Pakistan is among the top 15 countries suffering from tobacco-caused comorbidities and mortality along with almost 24 million tobacco users in the country. ${ }^{11}$

Vitamin $E$ is a lipid-soluble compound that includes four tocopherols and four tocotrienols. ${ }^{12}$ Among different types of Vitamin E, Alphatocopherol has the highest biological activity..$^{13}$ It is a natural, lipid-soluble antioxidant that is known to defend biological membranes and lipoproteins from oxidative stress. ${ }^{14}$

The current study was done to educate smokers about the risks and damaging effects of relatively modern and innocent looking E-cigarette device on adrenal gland which is responsible for production of vital hormones involved in various homeostatic functions in body.

\section{MATERIAL \& METHODS}

Our current study was a randomized control trial performed at animal house in National Institute of Health (NIH) Islamabad, from September 2018 to September 2019. Thirty male adult rats, weighing between 250 to 300 grams were kept in three cages, 10 rats per cage. The simple random sampling technique was used to for rats allocation. The research was approved by Ethical Review Committee of Islamic International Medical College, Rawalpindi. A controlled standard living environment suitable for rats with diet was provided. A well ventilated room with cycle of 12 hours light and 12 hours dark was maintained under 20 to 26 degrees Celsius. The adult rats of age 3 to 4 months were included in our current study and those rats with any known pathology and female gender were excluded. 30 rats were randomly divided into three groups.
- Group I (Control Group, n = 10)

Control group rats were given standard laboratory diet orally and drinking water ad libitum for 4 weeks.

- Group II (E-cigarette group $n=10)$

Group II rats were injected with an intraperitoneal injection of E-cigarette liquid containing $0.5 \mathrm{mg}$ of nicotine $/ \mathrm{kg}$ of body weight/day diluted in normal saline $(500 \mu \mathrm{l})$ for 4 weeks.

- Group III (E-cigarette with vitamin E group n $=10)$

Group III rats received vitamin E (100mg/kg body weight daily) mixed in daily food and an intraperitoneal injection of E-cigarette liquid containing $0.5 \mathrm{mg}$ of nicotine $/ \mathrm{kg}$ of body weight/day diluted in normal saline $(500 \mu \mathrm{l})$ for 4 weeks.

After completion of the 4 weeks of experimental research the rats were euthanized, dissected and the adrenal gland was removed. After fixation and embedding, eosin and hematoxylin stains were used for histological sections. The slides were examined in detail under 10x and 40x power of light microscope. The microscopic qualitative parameters observed include cell orientation, vacuolization, sinusoidal dilation and necrosis in all zones of adrenal cortex. Gross parameters included weight of adrenal gland. These parameter were assessed by one way analysis of variance (ANOVA) and Post hoc Tuckey's test for multiple comparisons between these groups.

\section{RESULTS}

In control group (Group I), all the animals showed normal histological features under the light microscope. The orientation of zona glomerulosa cell was in form of a cluster and regularly arranged cells, seprated from other cells by means of normal blood sinusoids, (Figure-1) (Table-I). In zona fasiculata the cell were regularly arranged in the form of straight cords with normal blood sinusoids separating the two cords from one another, (Figure-2) (Table-II). In zona reticularis, cells were arranged regularly in branching cords with normal sinusoids inbetween, (Figure-3) (Table-III). 
In E- cigarette group (Group II), the animals showed irregularity in the orientation of the cell with dilatation of sinusoids in ZG, (Figure-1) (Table-I). In ZF, cells showed irregular arrangement with significant sinusoidal dilatation between them, (Figure-2) (Table-II). In ZR, cells showed irregular orientation of cells with sinusoidal dilatation, (Figure-3) (Table-III). In E- cigarette and vitamin E group (Group III), rats showed regular cellular orientations in all zones of adrenal cortex with only minimal sinusoidal dilatation which was not significant.

\section{Morphomerteric Measurments}

1. Mean weight of rat Adrenal gland in control group was $27.708 \mathrm{mg}$ while in E-cigarette group II it was increased to $36.751 \mathrm{mg}$.In E-cig with Vit E group III, mean weight was 29.216 mg which was near to the normal weight of Adrenal gland of control group, (Table-I and II).

The mean thickness of adrenal gland in the control group I,II and III was 405.40um. 519um and 436um respectively. The result highlighted that the Vitamin $\mathrm{E}$ has significantly restored the effect of E-Cigarette on adrenal cortex thickness in group III, (Figure-4).

\begin{tabular}{|c|c|c|c|c|c|c|c|c|}
\hline & \multicolumn{8}{|c|}{ Sinusoidal dilatation in differnt zones of adrenal cortex $(\mathrm{N}=\%)$} \\
\hline & Groups & Normal & Minimal & Mild & Moderate & Severe & $95 \% \mathrm{Cl}$ & P- Value \\
\hline \multirow{3}{*}{ ZG } & I(control) & $10(100 \%)$ & $0(00 \%)$ & $0(00 \%)$ & $0(00 \%)$ & $0(00 \%)$ & $0.00-0.00$ & \multirow{3}{*}{$0.000^{*}$} \\
\hline & II(E-Cig) & $0(00 \%)$ & $4(40 \%)$ & $4(40 \%)$ & $2(20 \%)$ & $0(00 \%)$ & $1.39-2.81$ & \\
\hline & III(E-Cig+Vit E) & $5(50 \%)$ & $4(40 \%)$ & $1(10 \%)$ & $0(00 \%)$ & $0(00 \%)$ & $0.31-1.89$ & \\
\hline \multirow{3}{*}{ ZF } & I(control) & $10(100 \%)$ & $0(00 \%)$ & $0(00 \%)$ & $0(00 \%)$ & $0(00 \%)$ & $-0.10-0.90$ & \multirow{3}{*}{$0.000^{*}$} \\
\hline & II(E-Cig) & $0(00 \%)$ & $0(00 \%)$ & $1(10 \%)$ & $2(20 \%)$ & $7(70 \%)$ & $3.10-4.10$ & \\
\hline & III(E-Cig + Vit E) & $4(40 \%)$ & $2(20 \%)$ & $4(00 \%)$ & $0(00 \%)$ & $0(00 \%)$ & $0.33-1.67$ & \\
\hline \multirow{3}{*}{ ZR } & I(control) & $10(100 \%)$ & $0(00 \%)$ & $0(00 \%)$ & $0(00 \%)$ & $0(00 \%)$ & $0.00-0.00$ & \multirow{3}{*}{$0.000^{*}$} \\
\hline & II(E-Cig) & $0(00 \%)$ & $1(10 \%)$ & $3(30 \%)$ & $1(10 \%)$ & $5(50 \%)$ & $2.17-3.83$ & \\
\hline & III(E-Cig+Vit E) & $3(30 \%)$ & $3(30 \%)$ & $4(40 \%)$ & $0(00 \%)$ & $0(00 \%)$ & $0.47-1.73$ & \\
\hline
\end{tabular}

Table-I. Group wise distribution of sinusoidal dilatation in Zona Glomerulosa, Zona Fasciculata and Zona Reticularis cells, among all groups.

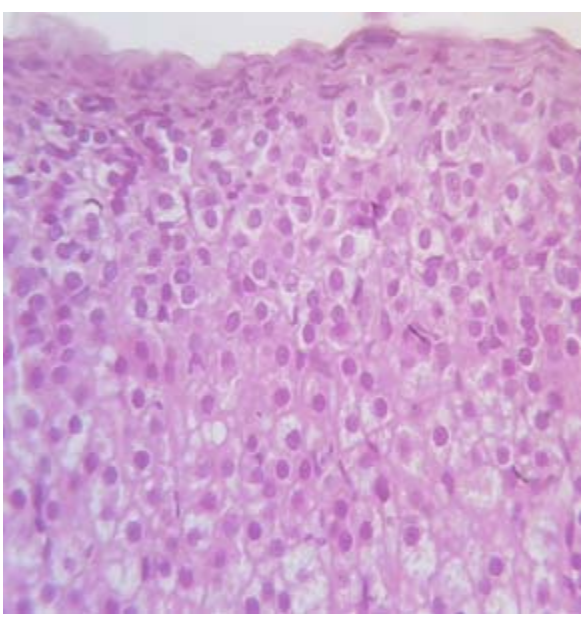

Group- I

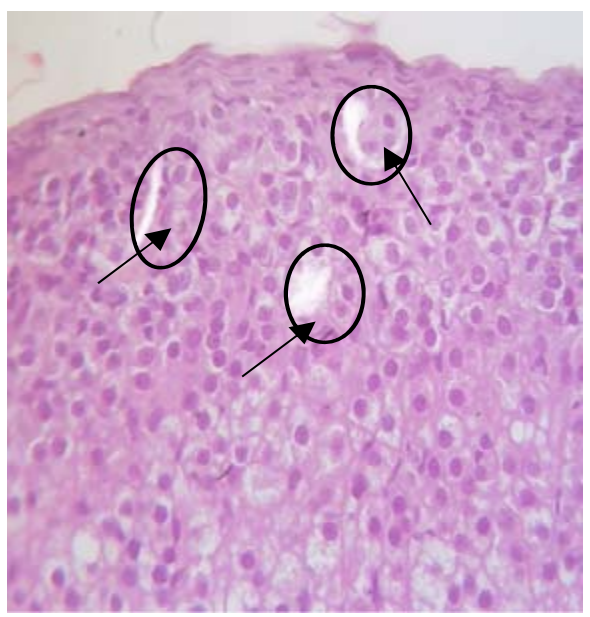

Group-II

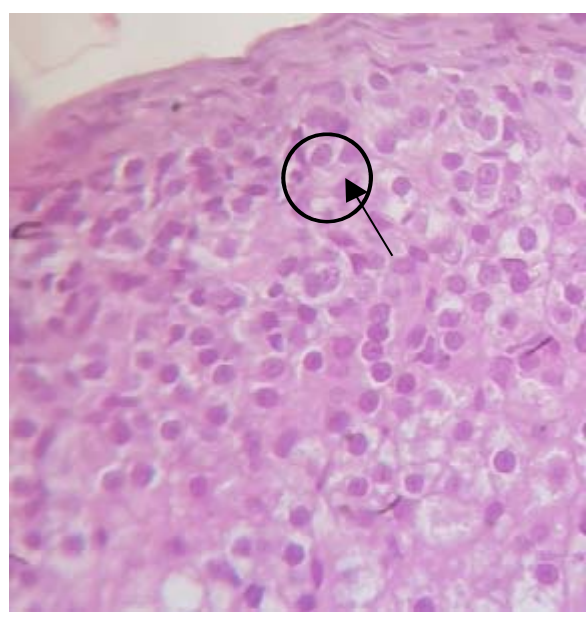

Group-III

Figure-I. Normal sinusoid in Zona Glomerulosa of group I, sinusoidal dilation in group II shown in three circles with arrows and mild sinusoidal dilation in group III shown in a circle with an arrow, (H and E, X 40). 


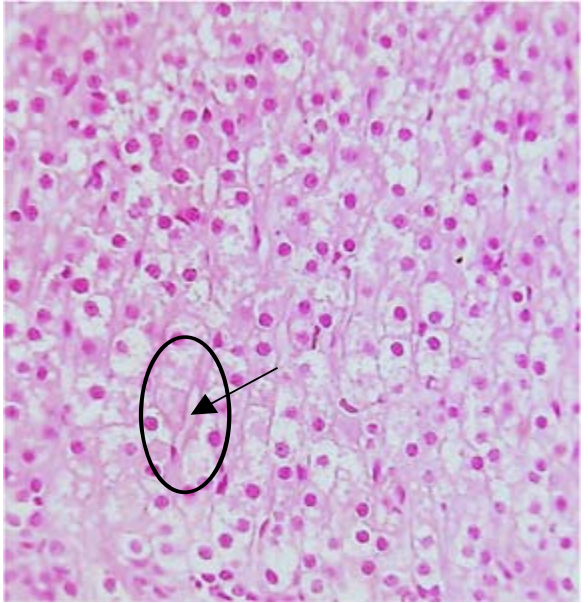

Group- I

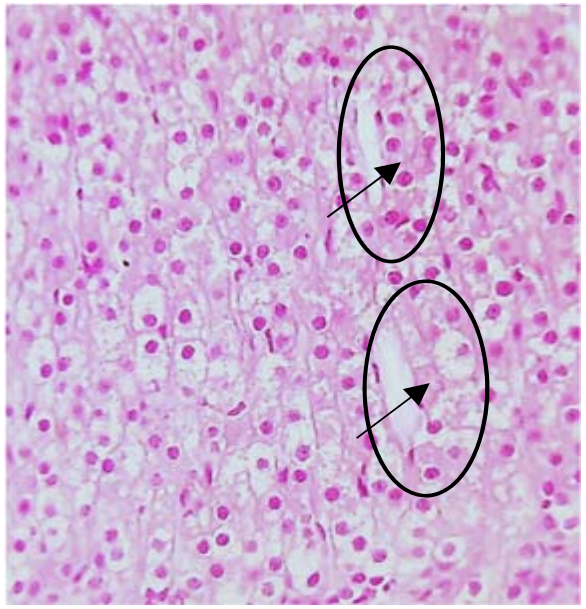

Group-II

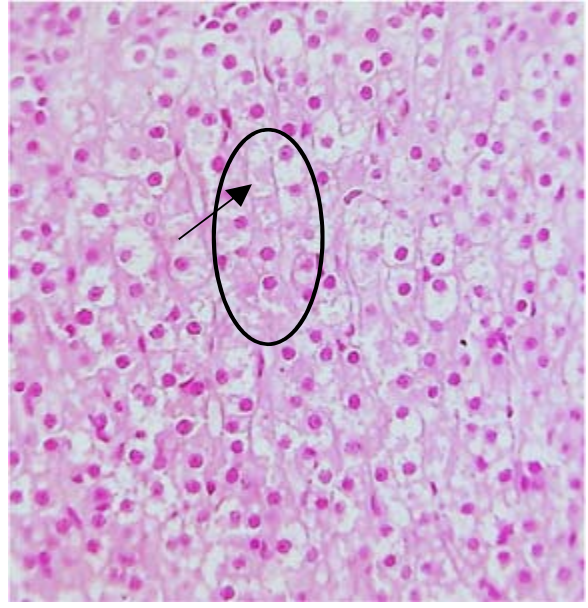

Group-III

Figure-II. Normal sinusoid in Zona Fasiculata of group I shown in a circle with an arrow, severe sinusoidal dilation in group II shown in two circles with an arrow and mild sinusoidal dilation in group III shown in a circle with an arrow, ( $H$ and $E, X 40)$.

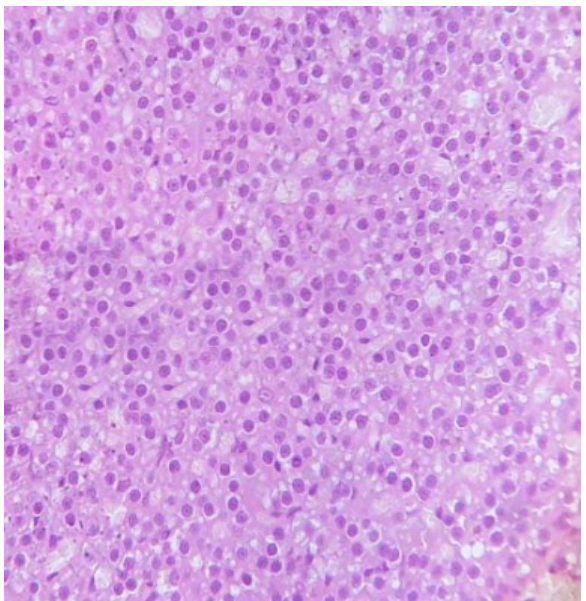

Group- I

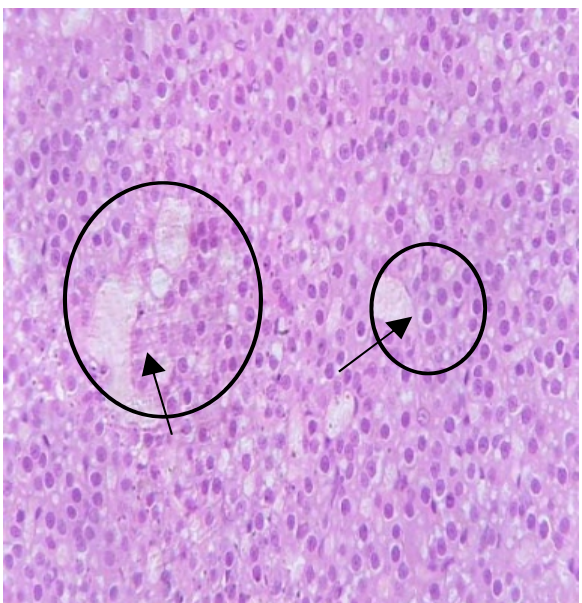

Group-II

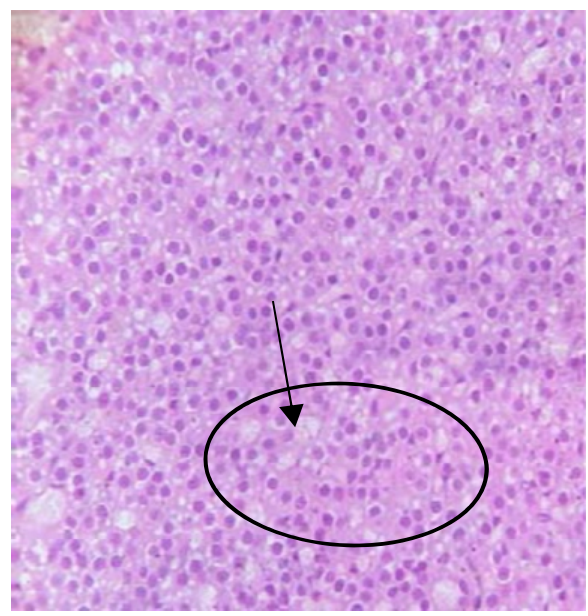

Group-III

Figure-III. Normal sinusoid in Zona Reticularis of group I, severe sinusoidal dilation in group II shown in two circles with arrows and mild sinusoidal dilation in group III shown in a circle with an arrow, ( $\mathrm{H}$ and E, X 40).

\begin{tabular}{|c|c|c|c|c|}
\hline \multicolumn{5}{|c|}{ Weight of adrenal gland(mg) } \\
\cline { 1 - 3 } Groups & Mean & SEM & $95 \%$ CI & P- Value \\
\hline I & 27.70 & 0.41 & $26.77-28.64$ & \\
\hline II & 36.75 & 0.56 & $35.48-38.01$ & \multirow{2}{*}{$* 0.000$} \\
\hline III & 29.21 & 0.41 & $28.27-30.15$ & \\
\hline
\end{tabular}

Table-II. Multiple comparisons of weight $(\mathrm{mg})$ of Adrenal gland among control and experimental groups. * $p \leq 0.05$
Weight of adrenal gland $(\mathrm{mg})$

\begin{tabular}{|c|c|c|c|}
\hline Groups & $\begin{array}{c}\text { Mean } \\
\text { Difference }\end{array}$ & $95 \%$ Cl & P-Value \\
\hline I vs II & 9.0 & $-10.68--7.40$ & $.000^{\star}$ \\
\hline I vs III & 1.50 & $-3.14-0.13$ & .076 \\
\hline II vs III & 7.53 & $5.89-9.17$ & $.000^{\star}$ \\
\hline
\end{tabular}

Table-IV. Average weight of Adrenal gland $(\mathrm{mg})$ of Albino Rats among control and experimental groups. ${ }^{*} \mathrm{p} \leq 0.05$ 


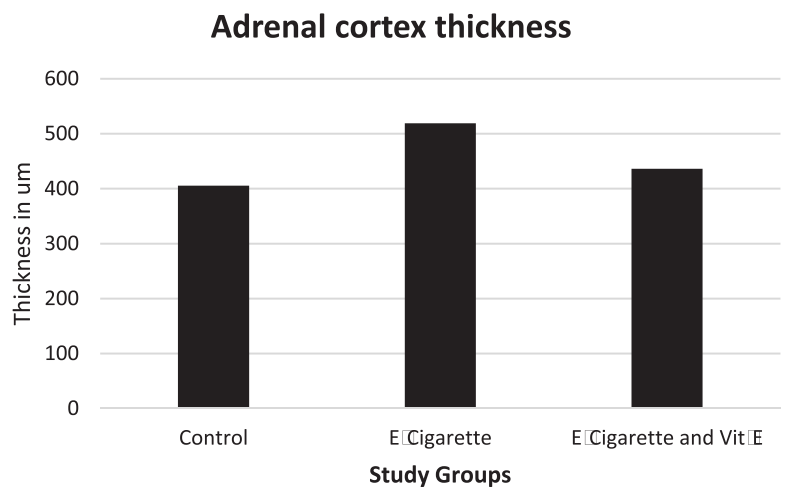

Figure-4. Thickness of Adernal cortex among all groups of Rats

\section{DISCUSSION}

The adrenal glands are one of the essential endocrine glands which perform numerous functions in the human body and are also known as life-saving glands. ${ }^{15}$ The cortex part of the adrenal gland secretes many different hormones. These hormones are mineralocorticoids, glucocorticoids and dehydroepiandrosterone. They control many functions of the body such as metabolism, anti-inflammatory reaction and regulate plasma concentration of different metabolites in body. ${ }^{16}$ These functions of adrenal cortex might be impaired by the influence of different environmental toxins. Nowadays in developing countries people are addicted to smoking cigarettes and are using newly introduced devices called E-cigarettes. Nicotine is the main component of E-cigarette which effects endocrine glands such as adrenal, pituitary, thyroid, ovarian and testicular functions. Nicotine causes disruption of antioxidant effects in adrenal cortex by increasing the lipid peroxidation and decreasing the antioxidant levels in tissue. Oxidative stress is due to the release of free radicles which cause oxidation of membrane phospholipid, in turn causes weakness of membrane and disrupts the cellular integrity. ${ }^{17,18}$ Therefore in this study, we used Vitamin E or Alpha Tocopherol as an antioxidant for ameliorating the effect of E-cig liquid induced histomorphological changes in male albino rats.

The result of our study determined that intraperitoneal exposure of E-cig. liquid containing nicotine had significant impact on the weight of adrenal glands of rats. Mean weight of the adrenal gland in group-II was significantly increased due to E-cigarette exposure. In group-III the increased weight of adrenal gland was restored up to control group. This proved that Vitamin E significantly decreased the effects of nicotine on the weight of adrenal gland which was increased due to the exposure of e-cigarette liquid. The increase in the weight of adrenal gland was due to exposure to nicotine contained in E-cigarette liquid. Nicotine causes swelling of the cells due to increased lipid contents in the form of vacuolization. ${ }^{19}$ These changes contributed to the significant increase in the total adrenal cortical thickness and thickness of cortical zones respectively. A study was conducted by Khalaf et al, which demonstrated the significant increase in weight of adrenal glands after 8 weeks of nicotine exposure. ${ }^{20}$ Similar result were observed in another study that showed significant increase in weight of adrenal gland which was ameliorated by Vit. C. ${ }^{19}$

In present study, the mean thickness of adrenal cortex in group-II was significantly increased, while in group-III the mean adrenal cortex thickness was significantly reduced to normal. In current study the increase in the total adrenal cortical thickness induced by nicotine was caused by inflammation in tissues resulting in increased cell size. A study conducted by the Iranloye et al, showed that the exposure of $0.5 \mathrm{mg} / \mathrm{kg}$ of nicotine for 30 and 60 days to the experimental rats increased the total adrenal cortex thickness of adrenal gland, this study strongly supports results of our present study. ${ }^{15}$

In present study, the parenchymal cells of all the adrenal cortical zones ZG, ZF and ZR were regularly arranged in control group-I. After the exposure of E-cig liquid containing nicotine to group-Il the orientation of ZG, ZF and ZR cells was significantly disorganized as compared to the control group-I. Administration of Vit-E to groupIII resulted in significant restoration of cortical cells orientation. A study conducted by Manal M. Sayed et al, demonstrated that nicotine at dose of $0.7 \mathrm{mg} / \mathrm{kg} /$ day markedly affected the orientation of adrenal cortex cells in all zones after 8 weeks. 
The nicotine in E-cig liquid effected the sinusoids by the formation of ROS which changed the permeability of endothelial cell membrane surrounding these sinusoids. Alteration in endothelial cell permeability due to nicotine in e-cigarette liquid lead to sinusoidal dilation. With chronicity, loss of adrenocortical parenchymal cell and consequent replacement with fibrous tissue may also lead to sinusoidal dilation. ${ }^{21}$ In present study all the zones of adrenal cortex ZG, ZF and ZR showed normal sinusoids in control group-I. But in group-II after the exposure of E-cigarette liquid to experimental animals, significant sinusoidal dilatation in all zones of adrenal cortex was seen. After the administration of Vit-E to group-III the sinusoidal dilatation was significantly improved. The sinusoidal dilatation was more prominent on those areas where cortical vacuolization and necrosis were also present. ${ }^{22}$ In a study conducted by yajio et al, liver sinusoidal dilation was caused by ROS was recovered by the use of Vitamin E. ${ }^{23}$

\section{CONCLUSION}

The current study clearly demonstrates that vitamin $E$ (Alpha-tocopherol) has an ameliorative effect on histological changes caused by E-cigarette liquid on adrenal cortex which included orientation of cortical cells, sinusoidal dilation, weight of adrenal gland and adrenal cortical thickness. This effect is due to antioxidant nature of Alpha-tocopherol. Alpha-tocopherol may be helpful to fight against E-cigarette induced histopathological damage to adrenal cortex. Therefore national and international health authorities should take steps to educate people about hazards of E-cigarette smoking and ban their sale and advertisements.

\section{Copyright@ 24 Sep, 2020.}

\section{REFERENCES}

1. Hillary S, Balasubramanian SP. Anatomy of the thyroid, parathyroid, pituitary and adrenal glands. Surgery (United Kingdom). 2017. p. 1-5.

2. Adamsson A. The effects of endocrine disrupters on fetal male rat testicular and adrenal development. 2009. 1-62 p.

3. Junqueira, Mescher AL. Junqueira's basic histology. In: lange, editor. junqueiras basic histology. 12th ed. McGraw Hill Medical; 2013. p. 444-9.
4. Ross M, Pawlina W. Histology, a Text and Atlas, Sixth Edition. Vol. 53, Journal of Chemical Information and Modeling. 2013. 1689-1699 p.

5. Yeung M, Tahir F. The pathology of pituitary, parathyroids, thyroid and adrenal glands. Surg (United Kingdom). 2017; 35(10):527-36.

6. Seki T, Yasuda A, Kitajima N, MS-20th E, 2018 U. Evaluation of adrenal function in cushing. endocrineabstracts.org. 2017; 1-13.

7. Callahan-Lyon P. Electronic cigarettes: Human health effects. Tob Control. 2014; 7:158-68.

8. Golli N El, Jrad-Lamine A, Neffati $\mathrm{H}$, Dkhili $\mathrm{H}$, Rahali $D$, Dallagi $Y$, et al. Impact of e-cigarette refill liquid exposure on rat kidney. Regul Toxicol Pharmacol. 2016; 77:109-16.

9. Schroeder MJ, Hoffman AC. Electronic cigarettes and nicotine clinical pharmacology. Tob Control. 2014; 23(2):30-4.

10. Khan J. E-cigarettes: A gateway to nicotine addiction? J Postgrad Med Inst. 2015; 29(4):213-4.

11. Shaheen K, Oyebode $\mathrm{O}$, Masud H. Experiences of young smokers in quitting smoking in twin cities of Pakistan: A phenomenological study. BMC Public Health. 2018; 18(1):1-12.

12. Maraqa A, Shraideh ZA, Shakya AK, Naik RR, ElAgbar ZA, Oriquat GA. Protective effects of Vitamin C, Vitamin $E$, and Beta-carotene against Nicotine induced oxidative damage to urinary system of albino rats. Fresenius Environ Bull. 2017; 26(2a):138996.

13. Patra RC, Rautray AK, Swarup D. Oxidative stress in lead and cadmium toxicity and its amelioration. Vet Med Int. 2011;2011:1-9.

14. Tweed JO, Hsia SH, Lutfy K, Friedman TC. The endocrine effects of nicotine and cigarette smoke. Vol. 23, Trends in Endocrinology and Metabolism. 2012. p. 334-42.

15. Iranloye BO, Bolarinwa a F. Effect of nicotine administration on estrous cycle in female albino rats. Niger J Heal Biomed Sci. 2008; 6(1):7-12.

16. Woodward GM, Rumsby G. Overview of adrenal physiology and steroid biochemistry. In: Disorders of Steroidogenesis. Springer International Publishing; 2019. p. 1-15. 
17. Ginzkey C, Stueber T, Friehs G, Koehler C, Hackenberg $S$, Richter E, et al. Analysis of nicotine-induced DNA damage in cells of the human respiratory tract. Toxicol Lett. 2012 Jan 5; 208(1):23-9.

18. Lee HW, Park SH, Weng M wen, Wang HT, Huang WC, Lepor $\mathrm{H}$, et al. E-cigarette smoke damages DNA and reduces repair activity in mouse lung, heart, and bladder as well as in human lung and bladder cells. Proc Natl Acad Sci U S A. 2018 Feb 13; 115(7):E1560-9.

19. Abdel-hamid GA. Ameliorative effect of vitamin C on nicotine-induced histological and ultrastructural changes in zona fasciculata in albino rats. Elsevier. 2018; (April):120-5.
20. Khalaf $H$, Ghoneim $F$, Arafat $E$, Mahmoud $E-H$. Histological effect of nicotine on adrenal zona fasciculata and the effect of grape seed extract with or without withdrawal of nicotine. J Microsc Ultrastruct. 2017; 5(3):123.

21. Magennis DP, McNicol AM. Vascular patterns in the normal and pathological human adrenal cortex. Virchows Arch. 1998; 433(1):69-73.

22. Mclnnes EF. Background lesions in laboratory animals. Background lesions in laboratory animals. Elsevier Inc.; 2011. 1-130 p.

23. Duan Y, Duan J, Feng Y, Huang X, Fan W, Wang K, et al. Hepatoprotective activity of Vitamin $E$ and metallothionein in cadmium-induced liver injury in Ctenopharyngodon idellus. Oxid Med Cell Longev. 2018; 2018:1-12.

\begin{tabular}{|c|c|c|c|}
\hline \multicolumn{4}{|c|}{ AUTHORSHIP AND CONTRIBUTION DECLARATION } \\
\hline Sr. \# & Author(s) Full Name & Contribution to the paper & Author(s) Signature \\
\hline 1 & Ali Ahmed & Principal Author & \\
\hline 2 & Mehreen Lashari & Author & \\
\hline 3 & M. Imran Bajwa & Corresponding Author & \\
\hline 4 & Jahanzaib Lashari & Author & 8 \\
\hline 5 & Syeda Sara Bano & Author & \\
\hline 6 & Dur Muhammad & Author & \\
\hline
\end{tabular}

